\title{
Achados patológicos, sinais clínicos e ganho de peso de coelhos infectados experimentalmente por Trypanosoma evansi
}

\section{Pathological findings, clinical signs and weight gain of naturally infected rabbits by Trypanosoma evansi}

\author{
Aleksandro Schafer da Silva ${ }^{1}$; Patrique de Lima Pereira ${ }^{2}$; Silvia Gonzalez Monteiro ${ }^{3 *}$
}

\section{Resumo}

O trabalho teve por objetivo avaliar os achados patológicos, sinais clínicos e ganho de peso de coelhos infectados experimentalmente por Trypanosoma evansi. Nove coelhos, machos com idade entre dois a seis meses, foram divididos em três grupos (A, B, C) com três animais cada. Os coelhos dos grupos A e B foram inoculados com $T$. evansi e avaliados diariamente através de esfregaço sanguíneo periférico. O grupo $\mathrm{C}$ foi utilizado como controle, isto é, inoculado somente com solução fisiológica. Os animais foram acompanhados por 120 dias e posteriormente sacrificados. Observou-se durante o experimento, que a parasitemia manteve-se com picos irregulares em variações de zero a cinco tripomastigotas/ campo por até 89 dias após a inoculação, desaparecendo da circulação após 90 dias. Não se observou alterações macroscópicas e microscópicas nos animais, no entanto, foram observados sinais clínicos como anorexia, apatia e mucosas pálidas, além de edema nas orelhas e pálpebras quando o número de protozoários aumentava na circulação periférica. Verificou-se que os animais parasitados por T. evansi apresentaram ganho de peso corporal inferior aos do grupo controle. Com base nos resultados, concluise que a infecção por T. evansi em coelhos acarreta alterações sistêmicas, embora os animais não venham a morrer em conseqüência da enfermidade.

Palavras-chave: Trypanosoma evansi, parasitemia, coelho, protozoário

\begin{abstract}
The study aimed to evaluate pathological findings, clinical signs and weight gain of naturally infected rabbits by Trypanosoma evansi. Nine male rabbits from two to six-month-old were divided into three groups (A, B, C) with three animals each. Rabbits from groups A and B were infected with T. evansi and evaluated daily through peripheral blood smears. Group $\mathrm{C}$ was used as control and the animals were inoculated with saline buffer only. The animals were sacrificed after 120 DPI. Irregular parasitemic peaks ranging from 0 to 5 trypomastigotes/field until 89 DPI, disappearing from circulation blood after 90 DPI. No macroscopically and microscopically alterations were observed in this study although the animals showed clinical signs as anorexia, apathy, pale mucosa and edema of the ears and eyelids when the number of protozoa increased into circulation blood. The animals infected by $T$. evansi showed lower body weigh gain than animals from the control group. The results showed that infection by $T$. evansi in rabbits is associated with systemic alterations although the animals did not die due to the consequences of the disease.
\end{abstract}

Key words: Trypanosoma evansi, parasitemia, rabbit, protozoan

\footnotetext{
1 Programa de Pós-Graduação em Medicina Veterinária da Universidade Federal de Santa Maria (UFSM), Santa Maria - RS, Brasil.

2 Bolsista de Iniciação Científica da UFSM, Santa Maria - RS, Brasil.

3 Departamento de Microbiologia e Parasitologia da UFSM, Santa Maria-RS. E-mail: sgmonteiro@uol.com.br.

* Autor para correspondência
} 
Trypanosoma evansi é comumente encontrado em reservatórios silvestres como capivaras, quatis, pequenos roedores e em animais domésticos como cão, eqüinos e suínos no Pantanal Matogrossense (HERRERA et al., 2004). Os tripanossomas são protozoários flagelados, digenéticos e seu ciclo vital envolve dois hospedeiros. As formas tripomastigotas do T. evansi presentes nos vasos sanguíneos de mamíferos são adquiridas pelo inseto durante repasto sangüíneo (SILVA et al., 2002), sendo considerado os Tabanídeos como principais vetores deste hemoparasita (JONES et al., 1997).

A tripanosomose causa sinais clínicos específicos em cães e eqüinos como anemia, edema de pernas, febre, letargia, perda de apetite, emagrecimento, aborto, perda de condição corporal, sangramentos nasais e oculares e manqueira, sendo fatal para estes animais (CARREIRA, 2005; SILVAetal., 1995). Jáas alterações histológicas freqüentemente encontradas em infecção por T. evansi em coelhos, ratos, eqüinos e cães são inflamatórias, degenerativas e necróticas principalmente no fígado, podendo ser observadas alterações macroscópicas e microscópicas no baço, pulmão e rins (BISWAS; CHOUDHURY; MISRA, 2001; KUBIAK; MOLFI, 1954; UCHE; JONES, 1992).

A infecção por Trypanosoma evansi em coelhos apresenta diferenças claras, pois a parasitemia e os sinais clínicos da doença não ocorrem em todos os animais que entram em contato direto com o parasito (UCHE; JONES; BOID, 1992). O objetivo deste estudo é avaliar os achados patológicos, sinais clínicos e ganho de peso de coelhos infectados experimentalmente por Trypanosoma evansi.

O experimento foi realizado em biotério experimental com temperatura e umidade controlada $\left(22^{\circ} \mathrm{C}\right.$ e $60 \%$ UR). Para a infecção dos animais, foi utilizada uma cepa do T. evansi oriunda de um cão naturalmente infectado do município de Uruguaiana, RS (COLPO et al., 2005), mantida em laboratório sob cultura viva em Rattus norvergicus.

Nove coelhos (Nova Zelândia), machos, com dois meses de idade, foram divididos em três grupos (A,
B, C). Os animais foram pesados nos dia 1, 20, 40, 60 e 120 . Através do exame parasitológico de fezes a partir da técnica de centrifugo flutuação com sulfato de zinco foi verificado que os coelhos apresentavam eimeriose. Durante o estudo foi feito o monitoramento dos animais com exame de fezes mensais.

No dia 1 os logmorfos dos grupos A e B foram inoculados via intra-peritonial com $0,5 \mathrm{ml}$ de sangue com T. evansi, nas concentrações de $10^{6}$ e $10^{4}$ tripomastigotas $/ \mathrm{ml}$, respectivamente. Os coelhos do grupo $\mathrm{C}$, grupo controle, foram inoculados com o mesmo volume de solução fisiológica e tratados nesse mesmo dia com anti-coccidiano (sulfa + trimetropim). Após 35 dias da infecção, os animais do grupo B foram tratados com a associação de sulfa e trimetropim, o mesmo procedimento não foi adotado para o grupo A, pois foi visado avaliar a influencia no ganho de peso em caso de duas infecções concomitantes (T. evansi e Eimeria).

A parasitemia foi analisada através de esfregaços sanguíneos periféricos diários. A técnica utilizada consiste na desinfecção da região auricular, perfuração da pele com agulha hipodérmica, retirada de uma gota de sangue, confecção do esfregaço sanguíneo em lâmina de vidro, coloração com Panóptico Rápido ${ }^{\circledR}$ e observação em microscópio óptico para pesquisa dos hemoparasitas com objetiva de 100x. Os animais foram avaliados por 120 dias.

Os animais foram sacrificados e necropsiados segundo as técnicas descritas por Lucca et al. (1996) e Oliveira, Alves e Rezende (2002). Na necropsia foram coletados fragmentos de fígado, baço, rim, pulmão, coração. Todos os fragmentos foram colocados em formol tamponado a $10 \% \mathrm{e}$ processados histologicamente para a pesquisa de alterações teciduais.

O presente experimento foi aprovado pelo Comitê de Ética e Bem-Estar Animal da Universidade Federal de Santa Maria (UFSM), n²3081.002690/2006-88, de acordo com legislação vigente e os Princípios Éticos publicados pelo Colégio Brasileiro de Experimentação Animal (COBEA). A análise estatística dos resultados de 
peso corporal dos animais foi feita através da análise de variância (ANOVA), seguida por aplicação do teste de TUKEY para comparação entre as médias e avaliar a precisão dos dados (SILVA; AZEVEDO, 2002).

Observou-se durante o experimento, que a parasitemia dos coelhos por $T$. evansi mantevese com picos irregulares em variações de 0 a 5 tripomastigotas/campo por até 89 dias após a inoculação, desaparecendo da circulação após 90 dias. Possivelmente neste estudo, as oscilações na parasitemia devem estar relacionadas aos anticorpos que têm propriedades que podem destruir parasitas e assim ocasionar a resistência nos coelhos, tornandoos reservatórios do flagelado (NUNES et al., 1993; UCHE; JONES; BOID, 1992).

A eimeriose manteve-se em grau leve no decorrer de todo o estudo no grupo A e nos grupos B e C não foi mais identificada após tratamento com anticoccidiano. Os grupos testados (A e B) não diferiram entre eles quanto ao grau de parasitemia e severidade dos sinais clínicos, não ocorrendo diferença em caso de uma simples infecção por T. evansi (grupo B) ou em caso de associada com Eimeria (Grupo A).

$\mathrm{Na}$ necropsia não foram observadas alterações macroscópicas, diferente do trabalho de Uche, Jones e Boid (1992) que identificaram esplenomegalia em coelhos infectados. Histologicamente as alterações encontradas nos órgãos afetados foram inespecíficas, além de que formas tripomastigotas do T. evansi não foram encontradas nos vasos viscerais. Uche e Jones (1992) em seu experimento com coelhos relataram alterações histológicas no fígado, pulmão, rim, baço e coração como: infiltração celular, degeneração gordurosa no fígado, glomerulite, edema pulmonar e necrose do miocárdio, porém no presente estudo estas alterações não estavam presentes, possivelmente devido a diferenças entre coelhos resistentes e suscetíveis ao T. evansi (UCHE; JONES; BOID, 1992).

No período de parasitemia, os coelhos apresentaram sinais clínicos como anorexia, apatia e mucosas pálidas, além de edema nas orelhas e pálpebras quando o número de tripanossomas encontrados no esfregaço sanguíneo periférico aumentava. Lesões nas orelhas e edema de pálpebras são alterações relatadas por Uche e Jones (1992), associadas no exame histopatológico a numerosos núcleos de tripanossomas no local da lesão. De acordo com Luckins, Mcintyre e Rae (1991) estas alterações estão relacionadas à reação inflamatória extensa devido ao rompimento de colágeno, edema, necrose da pele e infiltração de neutrófilos e linfócitos.

No final do experimento observou-se diferença estatística significativa entre os grupos avaliados referente ao peso corporal final (Tabela 1). Os grupos A e B apresentaram respectivamente peso corporal aproximadamente 30 e $25 \%$ inferior aos animais do grupo controle. Resultados semelhantes a estudo foram relatados por Uche, Jones e Boid (1992) em seu experimento, em que coelhos infectados com $T$. evansi apresentaram redução no peso corporal. Em cães e cavalos parasitados pelo protozoário a perda de peso é um sinal clínico típico da enfermidade (SILVA et al., 1995).

Tabela 1. Médias de peso corporal de coelhos infectados experimentalmente com T. evansi.

\begin{tabular}{lccccc}
\hline Grupos & \multicolumn{5}{c}{ Peso corporal (gramas) } \\
\cline { 2 - 6 } & Dia 1 & Dia 20 & Dia 40 & Dia 60 & Dia 120 \\
\hline A & $406^{\mathrm{a}}$ & $684^{\mathrm{a}}$ & $906^{\mathrm{a}}$ & $1310^{\mathrm{a}}$ & $2673^{\mathrm{a}}$ \\
$\mathrm{B}$ & $404^{\mathrm{a}}$ & $705^{\mathrm{a}}$ & $1040^{\mathrm{a}}$ & $1380^{\mathrm{a}}$ & $2881^{\mathrm{a}}$ \\
$\mathrm{C}$ & $408^{\mathrm{a}}$ & $691^{\mathrm{a}}$ & $1230^{\mathrm{b}}$ & $1855^{\mathrm{b}}$ & $3832^{\mathrm{b}}$ \\
\hline
\end{tabular}

Obs: Média seguida por letras iguais na mesma coluna não diferem estatisticamente entre si a $5 \%$ de probabilidade do teste de TUKEY. 
Com base nos dados, conclui-se que a infecção por T. evansi em coelhos acarreta alterações sistêmicas, embora os animais não venham a morrer em conseqüência do parasita, portanto não apresentam achados patológicos. A tripanossomíase interfere no ganho de peso dos logomorfos tanto com infecção simples por $T$. evansi quanto em uma infecção mista por T. evansi e Eimeria. Coelhos são susceptíveis a infeção experimental por T. evansi e apresentam sinais clínicos da doença.

\section{Referências}

BISWAS, D.; CHOUDHURY, A.; MISRA, K. K. Histopatology of Trypanosoma (Trypanozoon) evansi infection in bandicoot rat. I. visceral organs. Experimental Parasitology, New York, v. 99, n. 3, p. 148-159, 2001.

CARREIRA, J. C. Sanguessugas podem transmitir o mal das cadeiras, doença de equinos que tem grande importância econômica no Brasil. 2005. Disponível em: $<$ www.fiocruz.br/ccs/novidades/abr05/sanguessuga_adr. $\mathrm{htm}>$. Acesso em: 15 dez. 2005.

COLPO, C. B.; MONTEIRO, S. G.; STAINKI, D. R.; COLPO, T. B.; HENRIQUES, G. B. Infecção natural por Trypanosoma evansi em cão no Rio Grande do Sul. Ciência Rural, Santa Maria, v. 35, n. 3, p. 717-719, 2005.

HERRERA, H. M.; DAVILA, A. M.; NOREK, A.; ABREU, U. G.; SOUZA, S. S.; D'ANDREA, P. S.; JANSEN, A. M. Enzootiology of Trypanosoma evansi in Pantanal, Brazil. Veterinary Parasitology, Amsterdam, v. 125, n. 3-4, p. 263-275, 2004.

JONES, T. W.; PAYNE, R. C.; SUKANTO, I. P.; PARTOUTOMO, S. Trypanosoma evansi in the Republic of Indonesia. Proceedings of the first Internet Conference on Salivarian Trypanosomes, FAO, Animal Production and Health Paper. 1997. Disponível em: <www.fao.org/ docrep/W5781E/w5781e05.htm>. Acesso em: 19 jan. 2006.

KUBIAK, G. V. L.; MOLFI, A. Tripanosomíase eqüina (Mal das Cadeiras). Curitiba: Instituto de Biologia e Pesquisas Tecnológicas do Estado do Paraná, 1954. (Boletim, 33).
LUCA, R. R.; ALEXANDRE, S. R.; MARQUES, T.; SOUZA, N. L.; MOUSSE, J. L. B.; NEVES, P. Manual para técnicos em Bioterismo. São Paulo: Winner Graph, 1996.

LUCKINS, A. G.; MCINTYRE, N.; RAE, P. F. Multiplication of Trypanosoma evansi at the site of infection in skin of rabbits and cattle. Acta Tropica, Estocolmo, v. 50, n. 1, p. 19-27, 1991.

NUNES, V. L. B.; OSHIRO, E. T.; DORVAL, M. E. C.; GARCIA, L. A. M.; SILVA, A. A. P.; BOGLIOLO, A. R. Investigação epidemiologica sobre Trypanosoma (Trypanozoon) evansi no Pantanal Sul - Mato Grossense. Estudo de Reservatórios. Revista Brasileira de Parasitologia Veterinária, Rio de Janeiro, v. 2, n. 1, p. 41-44, 1993.

OLIVEIRA, H. P.; ALVES, G. E. S.; REZENDE, C. M. F. Eutanásia em medicina veterinária. 2002. Disponível em: <www.ufmg.br/coep/eutanasia.pdf $>$. Acesso em: 15 mar. 2006.

SILVA, F. A. S.; AZEVEDO, C. A. V. Versão do programa computacional Assistat para o sistema operacional Windows. Revista Brasileira de Produtos Agroindustriais, Campina Grande, v. 4, n. 1, p. 71-78, 2002.

SILVA, R. A. M. S.; HERRERA, H. M.; DOMINGOS, L.B.S.; XIMENES, F. A.; DÁVILA, A. M. R. Pathogenesis of Trypanosoma evansi infection in dogs and horses: hematological and clinical aspects. Ciência Rural, Santa Maria, v. 25, n. 2, p. 233-238, 1995.

SILVA, R.A. M. S.; SEIDL,A.; RAMIREZ, L.; DÁVILA, A. M. R. Trypanosoma evansi e Trypanosoma vivax: biologia, diagnóstico e controle. Corumbá: Embrapa Pantanal, 2002. Disponível em: <www.cpap.embrapa.br/ publicacoes/online/Livro015>. Acesso em: 15 jan. 2005.

UCHE, U. E.; JONES, T. W. Pathology of experimental Trypanosoma evansi infection in rabbits. Journal of Comparative Pathology, Oxford, v. 106, n. 3, p.299-309, 1992.

UCHE, U. E.; JONES, T. W.; BOID, R. Antibody patterns in rabbits showing different levels of susceptibility to an experimental Trypanosoma evansi infection. Acta Tropica, Estocolmo, v. 52, n. 2-3, p. 139-147, 1992. 